\title{
Fear of HIV Susceptibility Influencing Burden of Care among Nurses in South-East Nigeria
}

\author{
Ekaete Francis Asuquo $^{1 *}$, Prisca Adejumo ${ }^{2}$, Josephine Etowa ${ }^{1}$, Adebayo Adejumo $^{2}$ \\ ${ }^{1}$ Faculty of Health Sciences, School of Nursing, University of Ottawa, Ottawa, Canada; ${ }^{2}$ Department of Nursing, University of Iba- \\ dan, Ibadan, Nigeria. \\ Email: 'easuq095@uottawa.ca, ekaetefasuquo@yahoo.com
}

Received July $11^{\text {th }}, 2013$; revised August $9^{\text {th }}, 2013$; accepted August $15^{\text {th }}, 2013$

Copyright (C) 2013 Ekaete Francis Asuquo et al. This is an open access article distributed under the Creative Commons Attribution License, which permits unrestricted use, distribution, and reproduction in any medium, provided the original work is properly cited.

\begin{abstract}
HIV/AIDS currently is a major cause of disability and mortality especially in sub-Saharan Africa. As the population affected by HIV/AIDS increases, so does the burden of this chronic disease and the challenges associated with caring. HIV scourge in Nigeria has been overwhelming since 1992 with debilitating impacts and this study presents the extent of fear of susceptibility and the level of caregivers burden among Nigerian nurses. To direct the study, three special objectives and one hypothesis were raised, which were to determine the extent of fear of susceptibility and perceived seriousness of HIV, to ascertain the percentage of nurses who tested to know their HIV status and the associated level of caregivers burden among nurses. The study also determined the relationship between fear of susceptibility and caregiver's burden. A purposive sampling technique was used to select 210 nurses caring for people living with HIV/AIDS in the University of Calabar Teaching Hospital, Nigeria. Structured questionnaires and relevant validated scales such as Zarit Burden Interview [1] and abridged Champion Health Belief Model Scale [2] were used to elicit data. Results revealed that the majority of $41.0 \%$ respondents nursed fear of susceptibility despite the practice of universal precaution and perceived HIV as a serious and life threatening infection, $36.0 \%$ were not sure of their experience and $23 \%$ had no fear of HIV. 33.8\% respondents experienced mild to moderate level of burden, $27.2 \%$ respondents experienced moderate to severe level of burden while $15.7 \%$ experienced severe burden. A Chi Square value of 68.2 at $\mathrm{P}<0.05$ was obtained showing a significant relationship between fear of susceptibility and caregivers burden. This paper discusses the implications of these findings for nursing and health care and recommends the implementation of educational opportunities to allay fears and minimize caregiver burden among nurses and other health care professionals.
\end{abstract}

Keywords: HIV/AIDS Susceptibility; Caregivers’ Burden; Nurses; Nigeria

\section{Introduction}

HIV/AIDS has become one of the greatest public health challenges of our time, with about 34 million people globally living with HIV at the end of 2011 [3]. The burden of this epidemic varies between the developing and the developed countries. With sub-Saharan Africa bearing the brunt and accounting for $69 \%$ (22.9 million) of the people living with HIV worldwide, it implies that 1 in every 20 adults (4.9\%) is affected with HIV [3]. Cross River State (study site) is in the South region of Nigeria with an HIV prevalence of $7.1 \%$ [4]. This high prevalence in Cross River State and Nigeria as a whole has increased the burden on the health care system and profound impact on its human resources with health workers

${ }^{*}$ Corresponding author. and their families directly affected and infected by the HIV virus [5]. In 2006 [6], 48 health workers were infected with HIV by occupational exposure in South Africa and in Malawi, reports of HIV infection among nurses resulted in migration of nurses to other professions [7]. Another report [8] indicates that out of 24,844 adults with HIV working in health care centers, nurses comprised of $21 \%$ of the healthcare personnel with HIV/AIDS. The fear of susceptibility to HIV through occupation has created unfavourable attitude among nurses and a constant issue of concern $[8,9]$.

The chronic nature of HIV with mandatory death outcome produces anxiety, over-safety practices and fears of occupational contagion among nurses [10,11]. Although studies have revealed that the occupational risk of HIV is low $[6,12]$, yet caring for people living with HIV/AIDS 
still produces a high level of physical, social and emotional consequences among nurses. A significant correlation has been found to exist between level of burden and taking up or maintaining caregiver's role and the higher the burden level, the lower the quality of care [13]. The fear of susceptibility or perceived vulnerability infers that an individual could be susceptible to illness in general [14] or the risk/probabilities of contracting a health disease [15]. The perceived susceptibility is associated with perceived severity and perceived threat to life especially when it is associated with HIV $[14,15]$. But there are conditional and unconditional susceptibilities to illnesses [16] such that even when an individual behaviour does not promote risk of HIV, occupational contagion becomes an issue with health workers and nurses in particular, since they remain in constant contact with their patients in their line of duty.

The fear of contagion [17] emanates from the surreptitious meaning that people from different cultures attach to HIV/AIDS, such as mysterious affiliation with death, or as a form of punishment from sexual promiscuity. Death is the feared and most objectionable of all human conditions, therefore if HIV symbolizes death, the fear of death is projected into the fear of HIV. Also common with most HIV/AIDS caregivers is the anxiety over safety practices and occupational susceptibility and these anxiety increases their levels of burden [18] and the fear of physical and social contagion also accompanies nurses' working day [5]. The fear of susceptibility has become a major plague that has threatened a caregiving role and heightened the burden of caregivers sometimes without basis for such fear [6,12,19-21]. Even family ties have been affected as family members fear hug and kisses from those infected with HIV [22]. Reports of unfavourable attitude of health workers towards HIV patient indicated that personal behaviour puts health workers at risk much more than occupational contagion $[19,23]$. Yet the need to eliminate these feelings of susceptibility becomes the panacea that will improve quality of care.

The concept of burden had been acknowledged since 1960 immediately following the report that burden was associated with caring for mentally ill relatives [24]. Researchers in recent times have conceptualized burden as two dimensional subjective/objective or a multidimensional construct with physical, emotional (psychological), social and financial appraisal of caregiving mostly by family caregivers $[25,26]$.

The unique role of nurses among other health care workers in ameliorating the burden of disease on the health care system, community and the global society as a whole has been recognized [27-29]. They are expected to implement new initiatives and policies without additional staffing thereby bearing the brunt of an increased disease burden [5]. With the challenge of HIV, they have become the battle axe to combat the epidemic and their activities ranging from caring for people living with HIV/ AIDS (PLWHA) to implementation of policies affiliated with HIV and measures to reduce HIV to where it is no longer a public health challenge. Little or no attention is given to the psychological as well as the social impact this epidemic has on the life of these caregivers $[8,10]$. Reports have shown high levels of stress and depression among the Niger Delta inhabitants of Nigeria, and attributed to increased anxiety among nurses due to fear of contagion [9], which is comparable to stress or burnout of those caring for cancer patient [18]. In Cape Town, South Africa, HIV had a lot of psychological impact on nurses which dramatically transformed their working life to that of stress and anxiety about fear of injury and disclosure, and ultimately impacted their family life, with feelings of hopelessness and guilt [5].

The social, physical, psychological and emotional impact of caring for PLWHA often increased the level of burden of caregivers and portrays them as targets of HIV-related prejudice and discrimination [30,31]. The social impact emanates from the stigma associated with HIV and caregivers are stigmatized as harbouring the HIV virus themselves besides caring for the sick [32]. This limits their socializing ability and inability to disclose such feeling to others or family members [30]. Case studies indicate that the burden of care increases with the impairment in functional activities and the duration of care [13] and a significant correlation exist between the number of caregiving tasks and caregivers burden [33]. As patients' dependency on caregivers increases, the level of burden on nurse rises [34].

With increased burden, the nurse may develop feelings of anger, grief, loneliness, burnt-out and resentment, which may lead to poor quality of care and ill health of the nurse. This is typical in caring for patients with AIDS who may be in the terminal stage of HIV infection. With typical obnoxious situation of one nurse to thirty in Nigeria [35,36] or a ratio of one is to fifty in Malawi [7], the burden experienced by nurses will be severe. Therefore, measuring the burden level of nurses in Nigeria and other sub-Saharan countries with high HIV/AIDS prevalence becomes imperative, as a higher level of burden has a synergistic effect on the wellbeing of those expected to combat the ravaging effect of HIV epidemic [26]. This study therefore assesses the level of caregivers burden, the extent of fear/feeling of susceptibility and perceived seriousness among nurses.

\section{Materials and Methods}

\subsection{Location of the Study}

This study was conducted at the University of Calabar Teaching Hospital (UCTH), a regional tertiary Hospital 
in Calabar metropolis, Nigeria (Figure 1). This hospital serves as referral center to other hospitals, health centers and other health institutions where HIV/AIDS patients are admitted. The study was informed by the high prevalence of HIV/AIDS in Calabar Urban (10.4\%) [4].

\subsection{Methods}

The study participants were nurses working in University of Calabar Teaching Hospital as at 2010. A purposive sampling technique was used to obtained data from nurses who were willing to participate in the study. All nurses who had been involved in care giving of PLWHA for a period of not less than one month were included in the study. About 221 nurses who were working in units with PLWHA responded and 210 completed the questionnaires. The study was submitted to the University of Calabar Teaching Hospital Ethics and Research Committee, who gave the approval for conducting the study. Informed consent was obtained from study participants following full description of the aim and objectives of study.

Data was collected using structured questionnaires, and relevant validated scales such as Zarit Burden Interview [1] and abridged Champion Health Belief Model Scale (CHBMS) [2]. The structured questionnaires consisted of 27 items ( 7 on demographic variable, 10 on fear of susceptibility and 10 on perceived seriousness). The CHBMS [2], which was developed for measuring perceived susceptibility to breast cancer, was modified and used to assess the perceived fear of susceptibility in rela- tion to HIV/AIDS among nurses. The scale is made up of 30 items with a 3-point Likert rating scale ranging from strongly disagree to strongly agree. Only 10 questions relating to perceived susceptibility and perceived seriousness of HIV/AIDS were used. The instrument had a reliability coefficient ranging from 0.88 to 0.92 . The Zarit Burden Interview (ZBI) scale was modified to nurses and was made up of 22 items also, to reflect the emotional, physical health and social impact of care giving on nurses while caring for PLWHA. The respondents indicated the discomfort they experienced of particular items on a 5-point Likert scale ranging from $0-4$. The total score ranged from 0 to 88 and a high score correlated with higher level of burden. The Psychometric properties of Zarit Burden Interview scale had been examined in many studies with an estimated internal consistency reliability of Chronbach's alpha range of 0.88 to 0.92 [25]. The instruments were pilot-tested on 20 nurses in General Hospital, Calabar. This was done to gain experience, applicability of the instrument to our environment and assess the understanding of the questions and as a result, modifications were made on some of the items to reflect nursing perspectives.

\subsection{Data Analysis}

The data collected were analysed using the Statistical Package for the Social Sciences (SPSS 16.0) software to generate the means and percentages of the values. By the application of inferential statistics (Chi-Square test), the

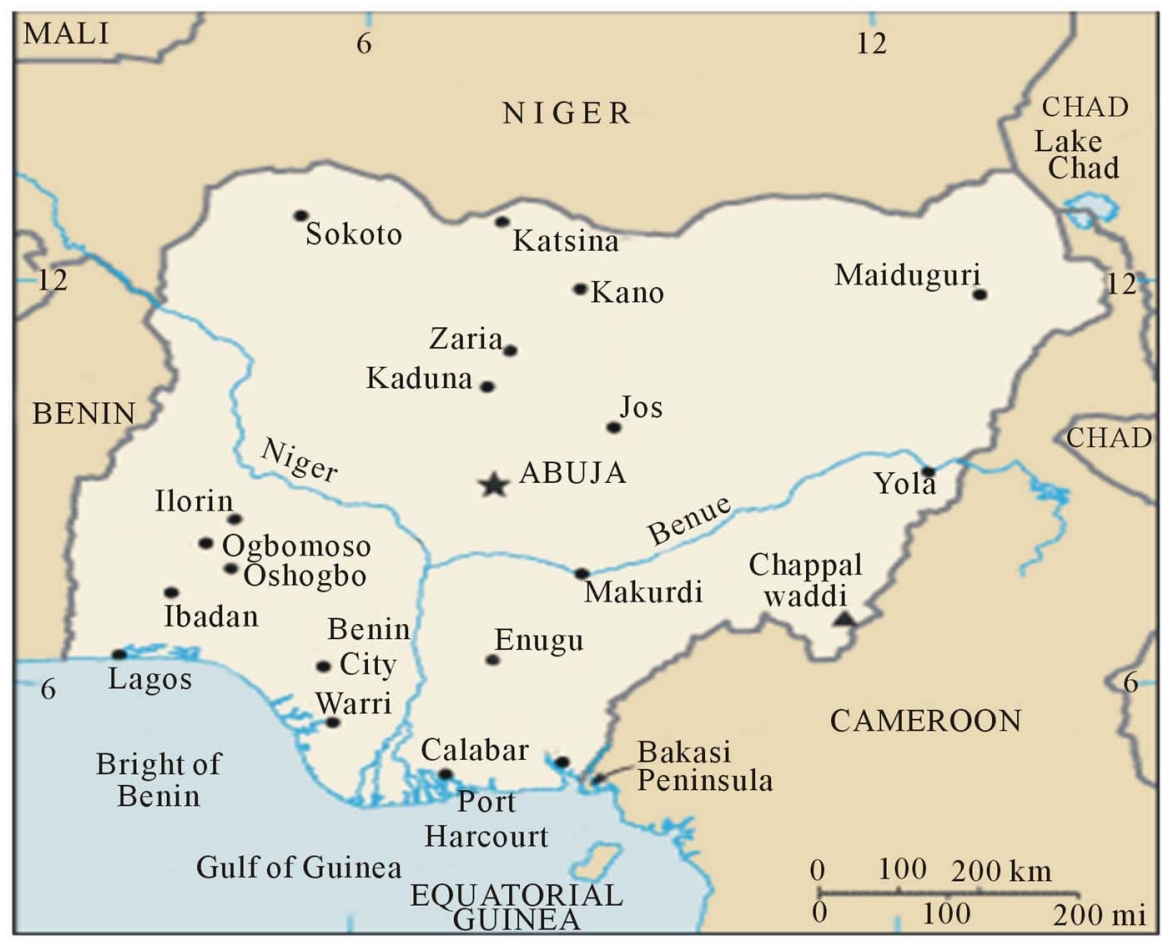

Figure 1. Map of Nigeria showing the location of Calabar, the study area. 
level of significance was also determined at the P-value of 0.05 . The Zarit interview scale had a reliability coefficient ranging from 0.88 to 0.92 . For level of burden, scores ranged from 0 to 88 . Zero to twenty $(0-20)$ represents little or no burden, $21-40$, mild to moderate burden; $41-60$, moderate to severe burden and $61-88$, severe burden [37]. The Champion Health Belief Model Scale (CHBMS) measuring approach of fear of susceptibility and percentages were used to grade those who have perceived susceptibility to HIV through caring.

\section{Results}

\subsection{Socio-Demographic Characteristics of Respondents}

A total of 221 nurses participated in the study (Table 1). Data from 210 participants were completely filled and

Table 1. Socio-demographic characteristics of respondents of study participants in Nigeria.

\begin{tabular}{|c|c|c|}
\hline Characteristics of respondents & Number & $\%$ \\
\hline Male & 2 & 0.95 \\
\hline Female & 208 & 99.05 \\
\hline \multicolumn{3}{|l|}{ Age (in years) } \\
\hline $21-31$ & 42 & 20 \\
\hline $31-40$ & 38 & 18.1 \\
\hline $41-50$ & 83 & 39.5 \\
\hline 51 years and above & 47 & 22.4 \\
\hline \multicolumn{3}{|l|}{ Religion } \\
\hline Christianity & 210 & 100.0 \\
\hline \multicolumn{3}{|l|}{ Marital Status } \\
\hline Married & 139 & 66.2 \\
\hline Single & 36 & 17.1 \\
\hline Divorcee & 31 & 14.8 \\
\hline Separated & 4 & 1.9 \\
\hline \multicolumn{3}{|l|}{ Occupational } \\
\hline status & 32 & 15.2 \\
\hline NO 1 & 30 & 14.3 \\
\hline NO 2 & 25 & 11.9 \\
\hline SNO & 60 & 28.6 \\
\hline $\mathrm{PNO}$ & 43 & 20.5 \\
\hline $\mathrm{ACNO}$ & 20 & 9.5 \\
\hline $\mathrm{CNO}$ & 25 & 11.9 \\
\hline Professional & 150 & 71.4 \\
\hline Qualification & 39 & 18.6 \\
\hline $\mathrm{RN} / \mathrm{RM}$ & 21 & 10.0 \\
\hline \multicolumn{3}{|l|}{ BNSC } \\
\hline $\mathrm{MSc}$ & & \\
\hline
\end{tabular}

analysed while 11 were discarded since their questionnaires were not completely filled. The majority 208 (99\%) respondents were female, $83(39.5 \%)$ in the age range of $41-50$ years. All were Christians by religion, and about 66\% (139 respondents) were married, while 18.6\% (39 respondents) had a first degree (BNSc) and above.

Nursing care giving role involves daily and close association of the nurse care giver with patient as long as she is on duty. From this study, $86(41.0 \%)$ respondents strongly agree that they experience fear of susceptibility, $77(36.7 \%)$ respondents neither agree nor disagree to fear of susceptibility, while $47(22.3 \%)$ respondents did experience fear of susceptibility (Table 2). The majority 72 $(34.3 \%)$ perceived HIV as a serious and life threatening infection, $71(33.8 \%)$ respondents neither agree nor disagree to seriousness of HIV while 67 (31.9\%) perceived it as not being life threatening (Table 3).

Among the 210 respondents who participated in the study, about $182(86.2 \%)$ respondents never tested to know their HIV status while $28(13.8 \%)$ had determined their HIV status (Figure 2).

The relationship between fear of susceptibility and care givers burden was significant among the respondents $\left(\mathrm{X}^{2}=68.2\right.$ at $\left.\mathrm{P}<0.05, \mathrm{n}=210\right)$, Tables 4 and $\mathbf{5}$. Out of 210, 47 respondents expressed no fear of susceptibility, 15 expressed they had burden of care while 32 had no burden. Seventy seven respondents were uncertain if they experienced fear of susceptibility or not, 67 experienced care givers burden and 10 respondents did not. Of about 86 respondents with fear of susceptibility, 7 had no burden while 79 experienced burden. A Chi Square value of 68.2 at $\mathrm{P}<0.05$ was obtained showing a significant relationship between fear of susceptibility and care givers burden. This indicates that the more the fear of susceptibility, the higher the care givers burden among the nurses and the lower the nursing services rendered to PLWHA.

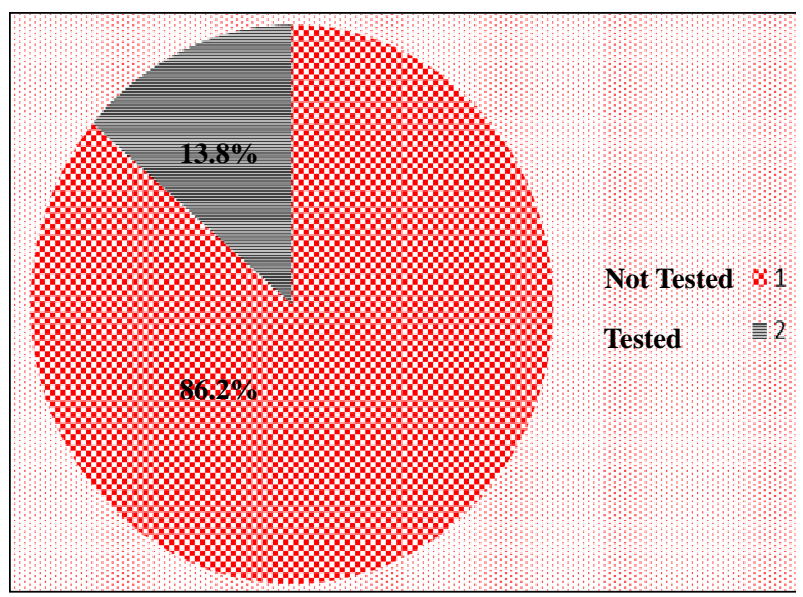

Figure 2. Pie chart showing the number of respondents who have undergone HIV testing. 
Table 2. Fear and feeling of susceptibility among nurses caring for PLWHA in Nigeria.

\begin{tabular}{|c|c|c|c|c|c|c|}
\hline \multirow{2}{*}{$\begin{array}{c}\text { Question (N = 210) } \\
\text { Susceptibility }\end{array}$} & \multicolumn{2}{|c|}{$\begin{array}{c}\text { Strongly } \\
\text { Disagree/Disagree }\end{array}$} & \multicolumn{2}{|c|}{$\begin{array}{l}\text { Neither Agree/Nor } \\
\text { Disagree }\end{array}$} & \multicolumn{2}{|c|}{$\begin{array}{l}\text { Strongly } \\
\text { Agree/Agree }\end{array}$} \\
\hline & $\mathbf{N}$ & $\%$ & $\mathbf{N}$ & $\%$ & $\mathbf{N}$ & $\%$ \\
\hline $\begin{array}{l}\text { It is extremely likely I may contact HIV/AIDS } \\
\text { in the future through my occupation }\end{array}$ & 62 & 29.5 & 99 & 47.2 & 49 & 23.3 \\
\hline I feel I may contact HIV/AIDS in the future through my occupation & 38 & 18.1 & 77 & 36.7 & 95 & 45.2 \\
\hline There is a good possibility I may contact HIV/AIDS in the next 10 years & 54 & 25.7 & 86 & 41 & 70 & 33.3 \\
\hline My chances of contracting HIV/AIDS through my occupation are great & 23 & 11 & 41 & 19.5 & 146 & 69.5 \\
\hline $\begin{array}{l}\text { I am more likely than the average nurse to contact } \\
\text { HIV/AIDS through my occupation }\end{array}$ & 59 & 28.1 & 82 & 39 & 69 & 32.9 \\
\hline If I am HIV/AIDS positive, I would not live longer than 5 years & 99 & 48.6 & 74 & 34.8 & 37 & 17.6 \\
\hline Total susceptibility score for all respondents & 47 & 22.3 & 77 & 36.7 & 86 & 41 \\
\hline
\end{tabular}

Table 3. Perceived Seriousness among nurses caring for PLWHAs in Nigeria.

\begin{tabular}{|c|c|c|c|c|c|c|}
\hline \multirow{2}{*}{$\begin{array}{c}\text { Question ( } \mathbf{N}=210) \\
\text { Seriousness }\end{array}$} & \multicolumn{2}{|c|}{$\begin{array}{c}\text { Strongly } \\
\text { Disagree/Disagree }\end{array}$} & \multicolumn{2}{|c|}{$\begin{array}{l}\text { Neither Agree/Nor } \\
\text { Disagree }\end{array}$} & \multicolumn{2}{|c|}{$\begin{array}{c}\text { Strongly } \\
\text { Agree/Agree }\end{array}$} \\
\hline & $\mathbf{N}$ & $\%$ & $\mathbf{N}$ & $\%$ & $\mathbf{N}$ & $\%$ \\
\hline I am afraid to think about HIV/AIDS & 25 & 11.9 & 71 & 33.8 & 114 & 54.3 \\
\hline Problems I would experience with HIV/AIDS would last a long time. & 62 & 29.5 & 102 & 48.6 & 46 & 21.9 \\
\hline $\begin{array}{l}\text { HIV/AIDS would threaten a relationship with } \\
\text { my boyfriend, husband or partner }\end{array}$ & 55 & 26.2 & 39 & 18.6 & 116 & 55.2 \\
\hline If I had HIV/AIDS my whole life would change & 95 & 45.2 & 69 & 32.9 & 46 & 21.9 \\
\hline Total seriousness score for all respondents & 67 & 31.9 & 71 & 33.8 & 72 & 34.3 \\
\hline
\end{tabular}

\section{Discussion}

The changing demographics in developing countries with "Youth bulge" (majority in population between the age of 15 and 30 years) have resulted in an increasing number of births in this sexually active age group [38]. Previous report [4] reveals that this age group is the worst hit with HIV/AIDS, which in turn will increase the burden of those caring for them but an improved technology and medical care could lead to improvement in life expectancy [38]. This improvement in turn results in an increase burden to care givers. These improvements in technology have also made patients to survive longer and continue treatment for a longer period of time. Even though this improvement is welcomed, it has also created major challenges for health care professionals especially the providers of curative and palliative cares who deliver emotional and practical support to patients living with terminal [39]. As population affected by HIV/AIDS increases, the burden of this chronic disease also grows. As treatment options have expanded, so have the stresses experienced by caregivers. Complementary to the stresses of caregiving is the associated fear of susceptibility especially in the presence HIV pandemic which has compounded care giving role.

Nurses, as professional care givers are well aware of the mode of transmission of HIV, but the fear of susceptibility as observed during this study was generally high among the formal care givers. In spite of the practice of universal precaution in the hospitals, minor injuries which are realized after removing gloves, and accidental tear of gloves also do occur. With constant care to PLWHA in their terminal stages, the fear of susceptibility through caring increases among these caregivers. These findings are similar to previous reports that some care givers are burdened by the fear of contracting HIV even when they know there is little or no basis for such concerns [6,12,19-22]. From a recent study [17], HIV is viewed as an affiliate of death, and as a form of punishment for sexual promiscuity. Therefore, it is not surprising to observe that most respondents in this study perceived HIV as a serious threat to life and their relationships, and are afraid to think about HIV/AIDS. These perceived seriousness influences their caregiving relationship to PLWHA. It has been revealed that perceived 
Table 4. The distribution of caregivers burden on Zarit Burden Interview scale (ZBI).

\begin{tabular}{cccc}
\hline Level of Burdens & $\mathbf{N}=\mathbf{2 1 0}$ & $\mathbf{\%}$ & Range \\
\hline No burden & 49 & 23.3 & $0-21$ \\
Mild to moderate burden & 71 & 33.8 & $21-40$ \\
Moderate to severe & 57 & 27.2 & $41-60$ \\
Severe burden & 33 & 15.7 & $61-88$ \\
Total & $\mathbf{2 1 0}$ & $\mathbf{1 0 0}$ & $\mathbf{8 8}$ \\
\hline
\end{tabular}

Table 5. The relationship between fear of susceptibility and care givers burden among study participants.

\begin{tabular}{cccc}
\hline Fear of Susceptibility & \multicolumn{2}{c}{ Burden } & Total \\
\hline & No Burden & Burden \\
No fear of susceptibility & $32(11.0)$ & $15(36.0)$ & 47 \\
Not sure of experience & $10(18.0)$ & $67(59.0)$ & 77 \\
Perceived fear of susceptibility & $7(20.1)$ & $79(65.9)$ & 86 \\
Total & $\mathbf{4 9}$ & $\mathbf{1 6 1}$ & $\mathbf{2 1 0}$ \\
\hline
\end{tabular}

Values in parentheses are expected frequencies; $\left(\mathrm{X}^{2}=68.2\right.$ at $\mathrm{P}<0.05$, DF 2 , $\mathrm{n}=210$ ).

susceptibility is associated with supposed severity and threat to life especially when associated with HIV [14, 15]. But amazingly, with the associated fear, most nurses refuse to undergo HIV test (Figure 2) and do not report about their feeling of susceptibility. This may be due to the psychological impact associated with HIV positivity which many health workers refuse to disclose such feelings to others or family members [30]. Culturally in Cross River State, Nigeria, it is believed that an individual is not tormented by what is not known, but knowledge about one's positivity arouses the emotional trauma and concerned persons start counting their days to the grave.

In this study, the significant relationship observed between fear of susceptibility and care givers burden (Table $4, X^{2}=68.2$ at $P<0.05$, DF $2, n=210$ ) suggests that the fear of susceptibility has a remarkable impact on the burden experienced by care givers. This may be associated with the fact that caregivers may dislike any care that brings them in close proximity with PLWHA as every contact may imply potential risk to HIV, therefore every move is threaded with caution. Most PLWHA especially at the terminal stage may lack many functional abilities and almost all activities of daily living are assisted or performed by the nurse. With a high fear of susceptibility, the nurse may be reluctant to respond to the nursing care routines of PLWHA as the need arises. This situation is worsened with the poor staffing condition of our hospitals that does not meet the World Health Or- ganisation standard of nurse patient-ratio [36], hence burden increased as workload increases.

These findings are comparable to previous reports [13, $33,34]$ where correlations were found between functional abilities of care receivers, care giving task, duration of care and the level of burden experienced by care givers respectively.

This therefore implies that as patients dependency on caregivers increases, the fear of contagion rises and nurses may develop feelings of burnout $[8,9]$. Such increased workload may lead to immigration of nurses to developed countries and to other professions $[7,18]$. The need to eliminate fear of susceptibility and reduce the burden experienced cannot be overemphasised, because reduced burden correlates with high quality of care and caregivers must function optimally (emotional, physical and social well being) in order to provide care receiver with the expected high quality care.

\section{Conclusion/Recommendation}

The ability to provide quality nursing care requires caregivers that are endowed with professional skills that overwhelm the feelings of fear of susceptibility during nursing practice. HIV infers death to many irrespective of retroviral drugs used and nurses are well aware of the seriousness of this deathly disease. Therefore, the level of burden of nurses caring for PLWHA increases due to fear of susceptibility. Increasing the number of nurses employed will also reduce their workload and lessen the level of burden.

Apart from the above, adopting a holistic approach towards reducing the fear of susceptibility among nurses must be encouraged through regular organization of continuing education programs, workshops and scientific conferences. Other educational resource avenues such as in-house seminars shall facilitate exchange of views, ideas and experiences between support groups, professional colleagues and caregivers which will ultimately reduce fear of susceptibility. Nurses should be encouraged to come together through such fora to share feelings and experiences, thereby learning from each other for a better appreciation of nursing a caregiving role. This process will enhance quality care and subsequent coping abilities of those caring for PLWHA.

\section{REFERENCES}

[1] H. Zarit, "Family Care and Burden at the End of Life," 2002.

[2] V. L. Champion, "Revised Susceptibility, Benefits, Barriers Scale for Mammography Screening," Research in Nursing \& Health, Vol. 22, No. 4, 1999, pp. 341-348. doi:10.1002/(SICI)1098-240X(199908)22:4<341::AID-N $\underline{\mathrm{UR} 8>3.0 . \mathrm{CO} ; 2-\mathrm{P}}$ 
[3] WHO, "Global Health Observatory (GHO)," Federal Ministry of Health (FMOH), 2011.

[4] "Technical Report: 2010 National HIV Sero-Prevalence Sentinel Survey," 2010.

[5] J. Zulu and U. Lehmann, "Investigating the Impact of the HIV/AIDS Epidemic on Nurses in 4 Primary Health Care Settings in Cape Town," Research Report on Study Funded by the Organization for Social Science Research in Eastern and Southern Africa, 2004.

[6] AVERT, "HIV/AIDS in South Africa," 2012. http://www.avert.org/aidssouthafrica.htm

[7] U. Kafulafuta, M. Hami and E. Chodzaza, "The Challenge Facing Nurse-Midwives in Working towards Safe Motherhood in Malawi," Malawi Medical Journal, Vol. 17, No. 4, 2005, pp. 125-127.

[8] S. Rekab Eslami Zadeh, "Knowledge and Attitude of Nurses towards Care of HIV/AIDS Patients," Journal of Academic and Applied Studies, Vol. 1, No. 1, 2011, pp. 39-51. www.academians.org

[9] P. Delobelle., J. L. Rawlinson, S. Ntuli, I. Malatsi, R. Decock and A. M. Depoorter, "HIV/AIDS Knowledge, Attitudes, Practices and Perceptions of Rural Nurses in South Africa," Journal of Advanced Nursing, Vol. 65, No. 5, 2009, pp. 1061-1073. doi:10.1111/j.1365-2648.2009.04973.x

[10] F. Abasiubong, E. Bassey, O. Ogunsemi and J. Udobang, "Assessing the Psychological Well-Being of Caregivers of People Living with HIV/AIDS in Niger Delta Region, Nigeria," AIDS Care, Vol. 23, No. 4, 2011, pp. 494-500. doi: 10.1080/09540121.2010.516340

[11] B. Ncama and L. Uys, "Exploring the Fear of Contracting Hiv/Aids among Trauma Nurses in the Province of Kwazulu-Natal," Curationispg, 2003, pp. 11-18. doi:10.4102/curationis.v26i2.774

[12] Health News, "HIV and the Acquired Immunodeficiency Syndrom Prevention of HIV Infection," 2006. http://www.health.am/aids/more/transmission_of_hiv to health care workers/

[13] National Alliance for Caregiving (NAC) and AARP, "Caregiving In the US," 2004. http://www.caregiving.org/data/04finalreport.pdf

[14] I. M. Rosenstock, V. J. Strecher and M. H. Becker, "The Health Belief Model and HIV Risk Behavior Change," In R. J. DiClemente and J. L. Peterson, Eds., Preventing AIDS: Theories and Methods of Behavioral Intentions, Plenum Press, New York, 1994, pp. 5-24.

[15] K. Witte, "Putting the Fear Back into Fear Appeals: The Extended Parallel Process Model," Communication Monographs, Vol. 59, 1992, pp. 329-349. doi: $10.1080 / 03637759209376276$

[16] D. L. Ronis, "Conditional Health Threats: Health Beliefs, Decisions, and Behaviors among Adults," Health Psychology, Vol. 11, 1992, pp. 127-134. doi:10.1037/0278-6133.11.2.127

[17] J. Meisenhelder, "Contributing Factors to Fear of HIV Contagion in Registered Nurses," Spring, Vol. 26, No. 1, 1994.

[18] V. Gueritault-Chalvin, S. Kalichman, A. Demi and J. Pe- terson, "Work-Related Stress and Occupational Burnout in AIDS Caregivers: Test of a Coping Model with Nurses Providing AIDS Care," Aids Care, Vol. 12, No. 2, 2000, pp. 149-161. doi:10.1080/09540120050001823

[19] W. Holzemer, "HIV Infection: Fear of Contagion, Reality of Risk," Japan Journal of Nursing Science, Vol. 5, No. 1, 2006, pp. 5-8. doi:10.1111/j.1742-7924.2008.00096.x

[20] J. O’Neill, K. Marconi, A. Surapruik and N. Blum, "Improving HIV/AIDs Services through Palliativecare and HRSA Perspectives," Journal of Urban Health, Vol. 77, No. 2, 2000, pp. 244-254. doi:10.1007/BF02390535

[21] B. Cowgill, L. Bogart, R. Corona, G. Ryan and M. Schuster, "Fears about HIV Transmission in Families with an HIV-Infected Parent: A Qualitative Analysis," Pediatrics, Vol. 122, No. 5, 2008, pp. 950-958. doi: $10.1542 /$ peds.2008-0390

[22] M. Schuster, M. Beckett, R. Corona and A. Zhou, "Hugs and Kisses: HIV-Infected Parents' Fears about Contagion and the Effects on Parent-Child Interaction in a Nationally Representative Sample," Archives of Pediatrics \& Adolescent Medicine, Vol. 159, No. 2, 2005, pp. 173-179. doi:10.1001/archpedi.159.2.173

[23] J. Pulerwitz, A. Annie Michaelis, E. Weiss, L. Brown and V. Mahendra, "Reducing HIV-Related Stigma: Lessons Learned from Horizons Research and Programs," Public Health Reports, Vol. 125, No. 2, 2010, pp. 272-281.

[24] J. Grad and P. Sainsbury, "Mental Illness and the Family," Lancet, Vol. 1, 1963, pp. 544-547. doi:10.1016/S0140-6736(63)91339-4

[25] K. Chou, H. Chu, C. Tseng and R. Lu, "The Measurement of Caregiver Burden," Journal of Medical Science, Vol. 23, No. 2, 2003, pp. 73-82. http://jms.ndmctsgh.edu.tw/2302073.pdf

[26] S. H. Zarit, K. E. Reever and J. Bach-Peterson, "Relatives of the Impaired Elderly: Correlates of Feelings of Burden," Gerontologist, Vol. 20, 1980, pp. 649-655. doi:10.1093/geront/20.6.649

[27] Institute of Medicine, IOM, "The Future of Nursing: Leading Change, Advancing Health," 2010. www.iom.edu/nursing.

[28] WHO, "PMTCT Strategic Vision 2010-2015: Preventing Mother-to-Child Transmission of HIV to Reach the UNGASS and Millennium Development Goals,” 2010. http://whqlibdoc.who.int/publications/2010 /9789241599030_eng.pdf

[29] Pan American Health Organization (PAHO), "Interim Policy on Collaborative TB/HIV Activities," World Health Organization Stop TB Department and Department of HIV/AIDS, 2004.

http://www1.paho.org/English/AD/DPC/CD/tb-hiv-policy .htm

[30] D. Singh, S. Chaudoir, M. Escobar and S. Kalichman, "Stigma, Burden, Social Support, and Willingness to Care among Caregivers of PLWHA in Home-Based Care in South Africa," AIDS Care: Psychological and Socio-Medical Aspects of AIDS/HIV, Vol. 23, No. 7, 2011, pp. 839845.

[31] W. Kipp, N. T. Matukala, L. Laing and G. S. Jhangri, 
"Care Burden and Self-Reported Health Status of Informal Women Caregivers of HIV/AIDS Patients in Kinshasa, Democratic Republic of Congo," AIDS Care, Vol. 18, No. 7, 2006, pp. 694-697. doi:10.1080/13548500500294401

[32] E. Monjok, A. Smesny and E. Essien, "HIV/AIDS-Related Stigma and Discrimination in Nigeria: Review of Research Studies and Future Directions for Prevention Strategies," African Journal of Reproductive Health, Vol. 13, No. 3, 2009, pp. 21-35.

[33] M. Pinquart and S. Sörensen, "Associations of Stressors and Uplifts of Caregiving with Caregiver Burden and Depressive Mood," A Meta-Analysis Journal of Gerontology: Psychological Sciences, Vol. 58, No. 2, 2003, pp. 112128. doi:10.1093/geronb/58.2.P112

[34] J. M. Argimon, E. Limon, J. Vila and C. Cabezas, "Health-Related Quality of Life in Carers of Patients with Dementia," Family Practice, Vol. 21, No. 4, 2004, pp. 454457. doi:10.1093/fampra/cmh418

[35] C. Obinna, "National Orthopaedic Hospital Enugu (NOHE) Seeks Improve Nurse Patient Ratio. Vanguard 29 June," 2009.
[36] WHO/UNICEF, "Global Monitoring Framework and Strategy for the Global Plan towards the Elimination of New HIV Infections among Children by 2015 and Keeping Their Mothers Alive (EMTCT): IATT M\&E WG M\&E Working Group of the Interagency Task Team on the Prevention and Treatment of HIV Infection in Pregnant Women, Mother, and Children," 2012.

[37] R. Hebert, G. Bravo and M. Preville, "Reliability, Validity and Reference Values of the Zarit Burden Interview for Assessing Informal Caregivers of Community-Dwelling Older Persons with Dementia," Canadian Journal of Aging, Vol. 19, No. 4, 2000, pp. 494-507. doi:10.1017/S0714980800012484

[38] National Population Bureau, "World Population Data Sheet," 2012.

http://www.prb.org/Publications/Datasheets/2012/world-p opulation-data-sheet.aspx

[39] J. McCann, L. Herbert, J. Bienias, M. Morris and D. Evans, "Predictors of Beginning and Ending Caregiving during a 3-Year Period in a Biracial Community Population of Older Adults," 2003. 